\title{
Black-Litterman Model with Views Prediction Using Elman Recurrent Neural Network
}

\author{
Dhoriva Urwatul Wutsqa ${ }^{1, *}$, Martina Ayun Pamungkas ${ }^{2}$, Retno Subekti ${ }^{1}$ \\ ${ }^{1}$ Department of Statistics, Universitas Negeri Yogyakarta, Yogyakarta, Indonesia \\ ${ }^{2}$ Department of Mathematics, Universitas Negeri Yogyakarta, Yogyakarta, Indonesia
}

Received August 7, 2021; Revised October 16, 2021; Accepted October 28, 2021

\begin{abstract}
Cite This Paper in the following Citation Styles
(a): [1] Dhoriva Urwatul Wutsqa, Martina Ayun Pamungkas, Retno Subekti, "Black-Litterman Model with Views Prediction Using Elman Recurrent Neural Network," Universal Journal of Accounting and Finance, Vol. 9, No. 6, pp. 1297 - 1311, 2021. DOI: 10.13189/ujaf.2021.090609.
\end{abstract}

(b): Dhoriva Urwatul Wutsqa, Martina Ayun Pamungkas, Retno Subekti (2021). Black-Litterman Model with Views Prediction Using Elman Recurrent Neural Network. Universal Journal of Accounting and Finance, 9(6), 1297 - 1311. DOI: 10.13189/ujaf.2021.090609.

Copyright $\odot 2021$ by authors, all rights reserved. Authors agree that this article remains permanently open access under the terms of the Creative Commons Attribution License 4.0 International License

\begin{abstract}
The Black-Litterman model is a portfolio model that considers investor views. The purpose of this study is to develop the Black-Litterman (BL) portfolio model with views prediction using Elman Recurrent Neural Network (ERNN) on LQ-45 stocks. The ERNN model is one of the neural network models that adjusts the input using the output feedback from the hidden layer. The BL portfolio is generated based on the capital assets pricing model (CAPM) excess return equilibrium. The data used in CAPM model must fulfill the normality assumption which is checked by using Jarque Bera test. The selected stocks for the portfolio are the member of LQ-45 stocks which meet the normality assumption and have the highest expected excess return CAPM value, those are AKRA, BBNI, INCO, and JSMR stocks. The ERNN model is employed to those stocks to obtain the views prediction. Then, the Black-Litterman portfolio is constructed by combining the ERNN views of the stock returns and the expected equilibrium return yielded by the capital assets pricing model. Three designs of relative views are considered, each design is distinguished from the percentage of each stock return prediction. The simulation shows that the best portfolio is constructed based on the design of the first views due to the most accurate views prediction.
\end{abstract}

Keywords Black-Litterman, Elman Recurrent Neural Network, Views Prediction, Portfolio

\section{Introduction}

Investment is a commitment to several funds or other resources carried out at this time, intending to obtain some benefits in the future [1]. Stocks are a profitable investment in the financial sector and are in great demand by the public. An investor can invest in several stocks by considering the risks borne. The higher the risk borne by the investor, the higher the expected rate of return. Investors need to form a portfolio or be able to diversify the investment to minimize risks [2]. This refers to Markowitz's old advice "don't put all the eggs in the same basket". This shows that in investing it is better to place capital in several stocks. This means that when one stock price decreases, the investor will not encounter a significant loss because it still has other stocks that possibly give profits.

One of the problems that arises in making decisions related to financial management including portfolio investment is how to integrate quantitative and judgmental managers. The existence of these two approaches can lead to conflict, harm the company, and make an unconducive situation. One of the portfolio models that accommodates both viewpoints is the Black Litterman model. The Black-Litterman model is powerful and has demonstrated the ability to increase the portfolio performance [3-4]. It develops the CAPM using a Bayesian approach to combine historical data (quantitative approach) and investors' views on balanced market conditions. This approach aims to address problems associated with the 
non-intuitive, highly concentrated portfolio, and sensitivity to input in the Markowitz model.

Investors' views on several stocks included in the portfolio are the issues that lead to the application of several forecasting models. Some researchers attempt many methods to determine the investors' views. The time series predictions for views on the BL model have been conducted by using the classical model ARIMA [5] and the fuzzy approaches [6]. Several studies concern with the problem of time-varying volatility in time series data. They accommodate that problem by implementing the EGARCH-M [7], GARCH [8], ARCH [9], and the combination of GARCH and Support Vector Regression [10]. Nowadays, many studies apply neural network (NN) models for time series forecasting without any specific data conditions such as stationary or time-varying volatility. The $\mathrm{NN}$ model has been shown to provide more accurate forecasting results than the GARCH model [11]. So, the NN model can be used as an alternative method to predict the views of each stock in the portfolio formation. The applications of NN have been reported for several stocks predictions using deep learning algorithms [12] and for the Nikkei 225 stock market index prediction using Genetic Algorithm optimization [13].

There are many types of NN models depending on the architecture and learning process or the estimation of weights or parameters. The type of NN widely used in predicting time series is the recurrent neural network (RNN) model. It is a type of $\mathrm{NN}$ that accommodates dynamic feedback networks. The input is updated using the output from the layer above it. This process makes the prediction results of the RNN model more accurate. Recurrent neural networks have caught the attention of researchers because they can be applied to model complex patterns that vary over time. Therefore, it is suitable for time series prediction.

The ERNN is a simple RNN with the feedback coming only from the hidden layer. The existence of feedback from hidden layers makes ERNN involve the current and past inputs so that ERNN can provide a representation of time-dependence well. The ERNN also allows managing relevant features prediction of an entire sequence. Numerous studies have shown the effectiveness of the ERNN model for predicting time series on various real data, such as for predicting the consumer price index for education, recreation, and sports in Indonesia [14], air quality, and [15], fault prediction method of the electronic equipment [16].

Based on the consideration of the superiority and effectiveness of the ERNN model, in this study, the view prediction is proposed using the ERNN model. Furthermore, the view prediction results are implemented to form a BL portfolio on the stocks of LQ-45 members. The LQ-45 index was first launched on February 24, 1997. This index consists of 45 stocks on the Indonesia Stock Exchange (ISE) with high liquidity and large market capitalization and passed the selection according to several selection criteria. The stock will include in LQ-45 if its average transaction value over the past 12 months ranks in the 60th largest of total stock transactions on the regular market. The stock has been recorded on the ISE for at least 3 months.

\section{Materials and Methods}

\subsection{Data}

This study uses monthly data of stock closing price included in the LQ-45 index for the period January 1, 2013, to December 1, 2019. All the stock closing price data used were obtained from the site www.yahoo.finance.com which was downloaded on December 20, 2019. We also use the data of risk-free interest rates obtained from the official website of Indonesian bank www.bi.go.id. We accessed them on 15 March 2020.

\subsection{EIman Recurrent Neural Network Model}

A recurrent Neural Network (RNN) is a type of neural network that accommodates network output to be used as network input again to produce new network output. The ERNN model is a neural network model that has a feedback connection located at a hidden layer [17]. The ERNN model consists of an input layer, a hidden layer, and an output layer. Additional neurons that occur in the connection between the input layer and the hidden layer in the previous time are called context units. The ERNN model is a two-way backpropagation network with additional neurons in the input layer coming from the hidden layer. The inputs of the ERNN model for time series forecasting are lags of time series variables. Suppose the time series $y_{t}$ is the output neuron, then $y_{t-1}, \ldots, y_{t-k}, \ldots, y_{t-m}$ are $m$ input neurons of the ERNN model. Let $z_{1}, \ldots, z_{j^{\prime}}, \ldots z_{p}$ are hidden neurons and $u_{1}, \ldots, u_{j}, \ldots, u_{p}$ are context units that come from the hidden layer. The ERNN architecture for time series data is presented in Figure 1. 


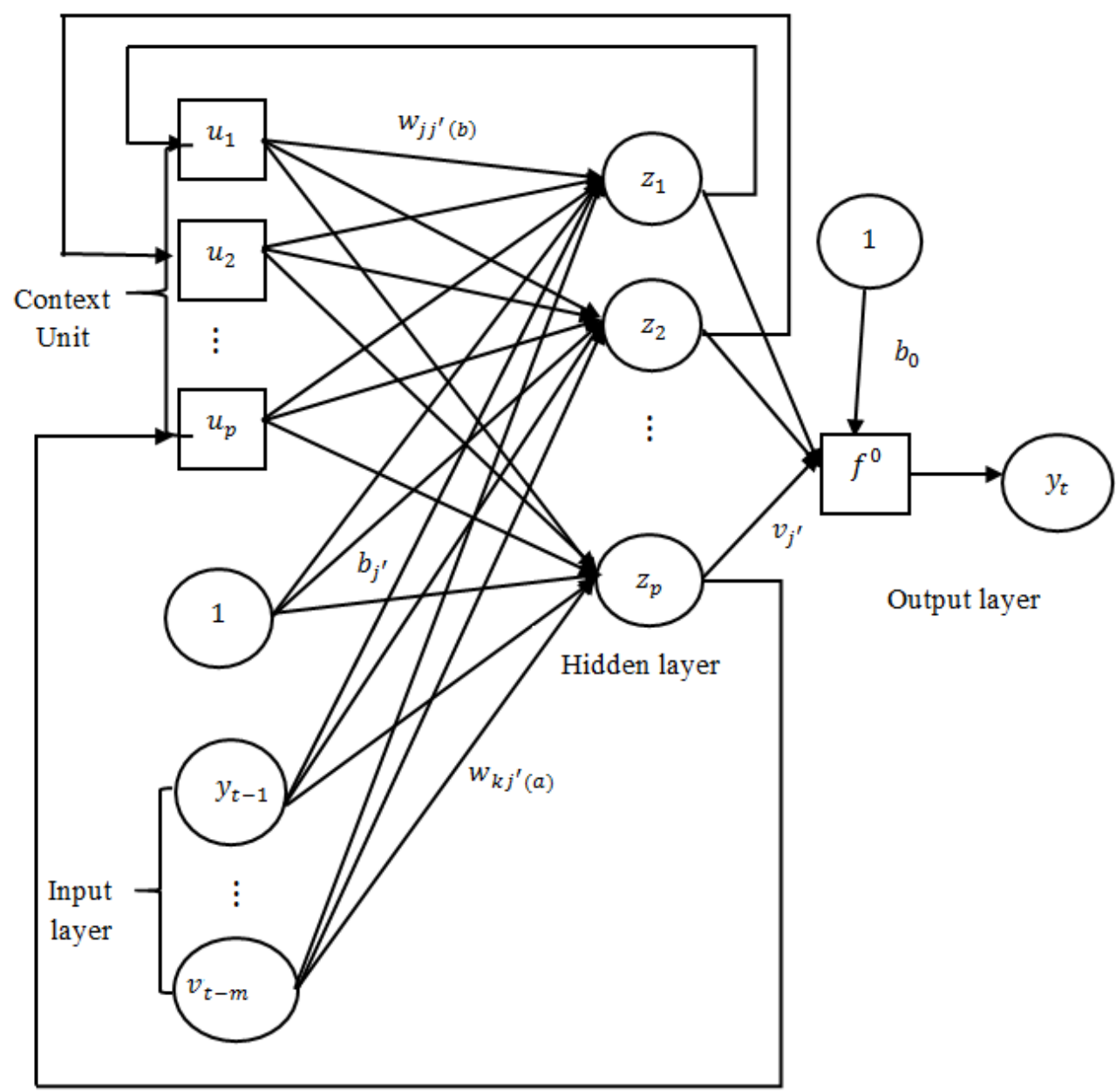

Figure 1. The ERNN architecture

The activation function in the hidden layer is bipolar sigmoid and in the output layer is linear. The ERNN model can be formulated as

$$
y_{t}=\sum_{j^{\prime}=1}^{p} v_{j^{\prime}} z_{j^{\prime}}+b_{0}+\varepsilon
$$

where

$$
Z_{j \prime}=\frac{1-\exp \left(-\left(\sum_{k=1}^{m} y_{t-k} w_{k j^{\prime}}(a)(a)+\sum_{j=1}^{p} u_{j} w_{j j^{\prime}(b)}+b_{j^{\prime}}\right)\right)}{1+\exp \left(-\left(\sum_{k=1}^{m} y_{t-k} w_{k j^{\prime}(a)}+\sum_{j=1}^{p} u_{j} w_{j j^{\prime}(b)}+b_{j^{\prime}}\right)\right)},
$$

$b_{j^{\prime}}$ is the bias of the $j^{\prime}$ th hidden neuron, $b_{0}$ is the bias of the output neuron, $w_{k j^{\prime}(a)}$ is the weight from the $k$ th input to the $j^{\prime}$ th hidden neuron, $w_{j j^{\prime}(b)}$ is the weight from the $j$ th context unit (additional neurons) to the $j^{\prime}$ th hidden neuron, and $v_{j^{\prime}}$ is the weight from the $j^{\prime}$ th hidden neuron to the output neuron.

\subsection{Black Litterman Model}

The Black Litterman model is a development of the CAPM that combines CAPM equilibrium return with investors' expected return views [18]. Investors' views are used to adjust the equilibrium expected return in predicting future returns. There are two types of views, namely absolute views and relative views [19]. Absolute views deal with investors who predict stock returns without comparing the stock returns. Meanwhile, relative views deal with investors who provide return predictions of two or more stocks by comparing the given returns. Those two pieces of information are combined using the Bayes rule, then the new BL expected return is expressed as follows:

$$
\boldsymbol{E}\left(\boldsymbol{r}_{\boldsymbol{B L}}\right)=\boldsymbol{\pi}+\tau \boldsymbol{\Sigma} \boldsymbol{P}^{\prime}\left(\boldsymbol{\Omega}+\boldsymbol{P} \tau \boldsymbol{\Sigma} \boldsymbol{P}^{\prime}\right)^{-1}(\boldsymbol{q}-\boldsymbol{P} \boldsymbol{\pi})
$$

and

$$
\boldsymbol{\pi}=\boldsymbol{E}\left(\boldsymbol{R}_{\boldsymbol{i}}\right)-\boldsymbol{R} \boldsymbol{f}
$$

where $\boldsymbol{\pi}$ is a matrix of CAPM excess equilibrium return, $\boldsymbol{E}\left(\boldsymbol{R}_{\boldsymbol{i}}\right)$ is a CAPM expected return, $R f$ is a risk-free asset, $\tau$ is a confidence level scale with range $0-1$, $\boldsymbol{\Sigma}$ is a covariance matrix of asset returns, $\boldsymbol{\Omega}$ is a diagonal of views error covariance matrix, $\boldsymbol{P}$ is a matrix of views coefficient, and $\boldsymbol{q}$ is a vector of return views given by the investor.

The value of $\tau$ is given by the investor to measure the historical covariance matrix $\boldsymbol{\Sigma}$. Satchell and Scowcroft [20] specify the value of $\tau$ as 1 , while He and Litterman [18] set the value of $\tau$ as 0,025 . The value of $\tau$ depends on the level of investor confidence in views, so the value of $\tau$ 
ranged between 0 and 1 . The $\pi$ component in this model is obtained based on CAPM information, where investors will invest in a balanced market condition. This means that investors will choose a market portfolio that consists of all risky assets.

The weights of the Black Litterman model referring to the Markowitz Mean Variance model can be written as

$$
\boldsymbol{w}_{B L}=(\delta \Sigma)^{-1} \boldsymbol{\mu}_{B L}
$$

where $\boldsymbol{w}_{\boldsymbol{B} \boldsymbol{L}}$ is a weight matrix of an asset in the BL model, $\delta$ is a risk aversion coefficient, $\boldsymbol{\Sigma}$ is a covariance matrix of asset returns, and $\boldsymbol{\mu}_{\boldsymbol{B} \boldsymbol{L}}$ is the Black Litterman expected return vector.

\subsection{The Procedure of BL Portfolio Formation using ERNN Views Prediction}

The formation of the BL portfolio model combines two sources of information, namely the equilibrium expected return obtained from the CAPM and the opinions /views of investors on the stocks. The process of establishing a BL portfolio with ERNN views prediction is carried out in the following steps:

\section{Step 1. Determine the stocks}

The initial step in forming a portfolio is choosing the stocks, then calculating the return of each stock. The normality assumption is tested on each stock using the Jarque Bera test, with the following test statistics [21]:

$$
J B=\frac{n}{6}\left[S^{2}+\frac{(K-3)^{2}}{4}\right]
$$

and

$$
S=\frac{1}{n} \sum_{t=1}^{n}\left(\frac{y_{t}-\bar{y}}{s}\right)^{3} \text { and } K=\frac{1}{n} \sum_{t=1}^{n}\left(\frac{y_{t}-\bar{y}}{s}\right)^{4}
$$

where $n$ is a sample size, $\mathrm{S}$ is a skewness coefficient, $K$ is a kurtosis coefficient, $y_{t}$ is an observed value at period $t$, $\bar{y}$ is an average, and $s$ is a standard deviation. If the stock is normally distributed then the calculation of the expected excess return of CAPM can be continued, whose value is the difference between CAPM's expected return and risk-free.

$$
E\left(R_{i}\right)-R_{F}=\beta_{i}\left[E\left(R_{M}\right)-R_{F}\right]
$$

The expected excess return CAPM is used for investor consideration in determining the stocks to be included in the portfolio.

\section{Step 2. Determine the views}

Views are determined based on the prediction of stock returns, which is calculated from the prediction of the monthly closing stock price. The price prediction process using the Elman Recurrent Neural Network model goes through the following stages. a) Determine the input

The network input is determined by looking at the autocorrelation plot on the monthly stock closing price data for the period January 1, 2013, to December 1, 2019. The input is the lag of the stock closing price variable, where the autocorrelation value differs significantly from zero. The test statistic is

$$
t=\frac{r_{k}}{S E\left(r_{k}\right)}
$$

where $S E\left(r_{k}\right)$ is the standard error of the autocorrelation coefficient at lag $\mathrm{k}$, it is defined as

$$
S E\left(r_{k}\right)=\sqrt{\frac{1+2 \sum_{i^{\prime}=1}^{k} r_{i^{\prime}}^{2}}{n}}
$$

where $r_{k}$ is an autocorrelation coefficient at lag $k$ [22]. The autocorrelation value differs significantly from zero if the absolute value of the $t$ test statistic is more than the value of $\mathrm{t}$ distribution with degree of freedom $n-1$.

\section{b) Divide the data}

The data are divided into 2 parts, namely training data and testing data. There are some compositions to divide the data, such as $80 \%$ for training and 20 for testing, $75 \%$ for training and $25 \%$ for testing, or $60 \%$ for training and $40 \%$ for testing [23]. In this study, we set $75 \%$ for training and $25 \%$ for testing.

\section{c) Form the best ERNN model}

In establishing the ERNN model, the data are normalized first. The learning process to determine the weights is carried out using the backpropagation algorithm [24]. The best model is obtained by determining the number of neurons in the hidden layer which gives the best predictive accuracy in training and testing data. Determination of the number of hidden layer neurons is employed by trial and error considering the MAPE (Mean Absolute Percentage Error) criterion. The MAPE formula is as follows [22]:

$$
M A P E=\frac{1}{n} \sum_{t=1}^{n} \frac{\left|e_{t}\right|}{y_{t}} \times 100 \%
$$

where $e_{t}$ is a residual at period $t, y_{t}$ is an observed value at period $t, n$ is the number of observations. The results of stock predictions are still in normal form, so it needs denormalization to replace the normalized value with its original form.

\section{d) Test error white noise}

After obtaining the ERNN model, the next step is to test the error white noise. If the autocorrelation coefficients and partial autocorrelation coefficients of the errors do not differ significantly from zero for all lags, the assumption of white noise is fulfilled. The test statistic for autocorrelation can be seen in (6). The test statistic for partial autocorrelation on lag $\mathrm{k}$ is 


$$
t=\frac{\widehat{\phi}_{k k}}{S E\left(\widehat{\phi}_{k k}\right)}
$$

where $S E\left(\hat{\phi}_{k k}\right)$ is the standard error of the partial autocorrelation coefficient at lag $\mathrm{k}$ [25]

$$
S E\left(\widehat{\phi}_{k k}\right)=\sqrt{\frac{1}{n}}
$$

where $\hat{\phi}_{k k}$ is a partial coefficient on lag $\mathrm{k}$. The $\mathrm{t}$ test statistic has $\mathrm{t}$ distribution with $n-1$ degree of freedom. This test can be done by looking at the ACF and PACF (Partial Autocorrelation Function) plots of the residual model. If in the ACF and PACF plots no coefficient exceeds the significant line, then the error is white noise and the model can be used for prediction. The predictive returns obtained from the ERNN model are used as the basis for investors to state the stock views. An investor can declare views on all stocks with absolute views, relative views, or use a mixture of both views.

\section{Step 3. Form the BL model portfolio}

Portfolios are formed based on views obtained from stocks predicted by the ERNN model. Then the BL expected return value is calculated using equation (2), the weight of each stock in the BL model is calculated using equation (3). The performance of portfolios is assessed whether it gives profits or losses at a certain time.

\section{Result and Discussion}

We take stocks of LQ-45 which survive from January 1, 2013, to December 1, 2019. The 38 stocks still survive in that period. A total of 24 out of 38 stocks meet the normality assumption. Then, the CAPM expected excess return values are calculated from those 24 stocks. In this study, we use stocks included in four sectors, namely trade, services, and investment; finance; mining; infrastructure, utilities, and transportation. Then, the stocks are selected by considering the representation and the highest expected excess return CAPM value in each sector. Thus, four stocks are selected to construct a portfolio, namely AKRA, BBNI, INCO, and JSMR. AKRA constitutes the stock of PT Akra corporindo Tbk, a company from the trade, services, and investment sector. BBNI constitutes the stock of Bank Negara Indonesia (State Bank of Indonesia), a company from the finance sector. INCO constitutes the stock of PT Vale Indonesia Tbk, a company from the finance sector. JSMR constitutes the stocks of Jasa Marga Tbk, a company from the infrastructure, utilities, and transportation sectors.

The BL portfolio model is developed using the information of excess return equilibrium CAPM $(\pi)$ and investor views (q). The $\pi$ value for each stock is presented in Table 1.

Table 1. The CAPM expected excess return

\begin{tabular}{|c|c|}
\hline Stock code & $\boldsymbol{\pi}$ \\
\hline AKRA & 0.00068 \\
\hline BBNI & 0.00112 \\
\hline INCO & 0.00055 \\
\hline JSMR & 0.00063 \\
\hline
\end{tabular}

The investor views are obtained from the return prediction of the ERNN model. The first step in establishing an ERNN model is determining the input and target using the ACF plot. The ACF plots for the four stocks are displayed in Figure 2. 

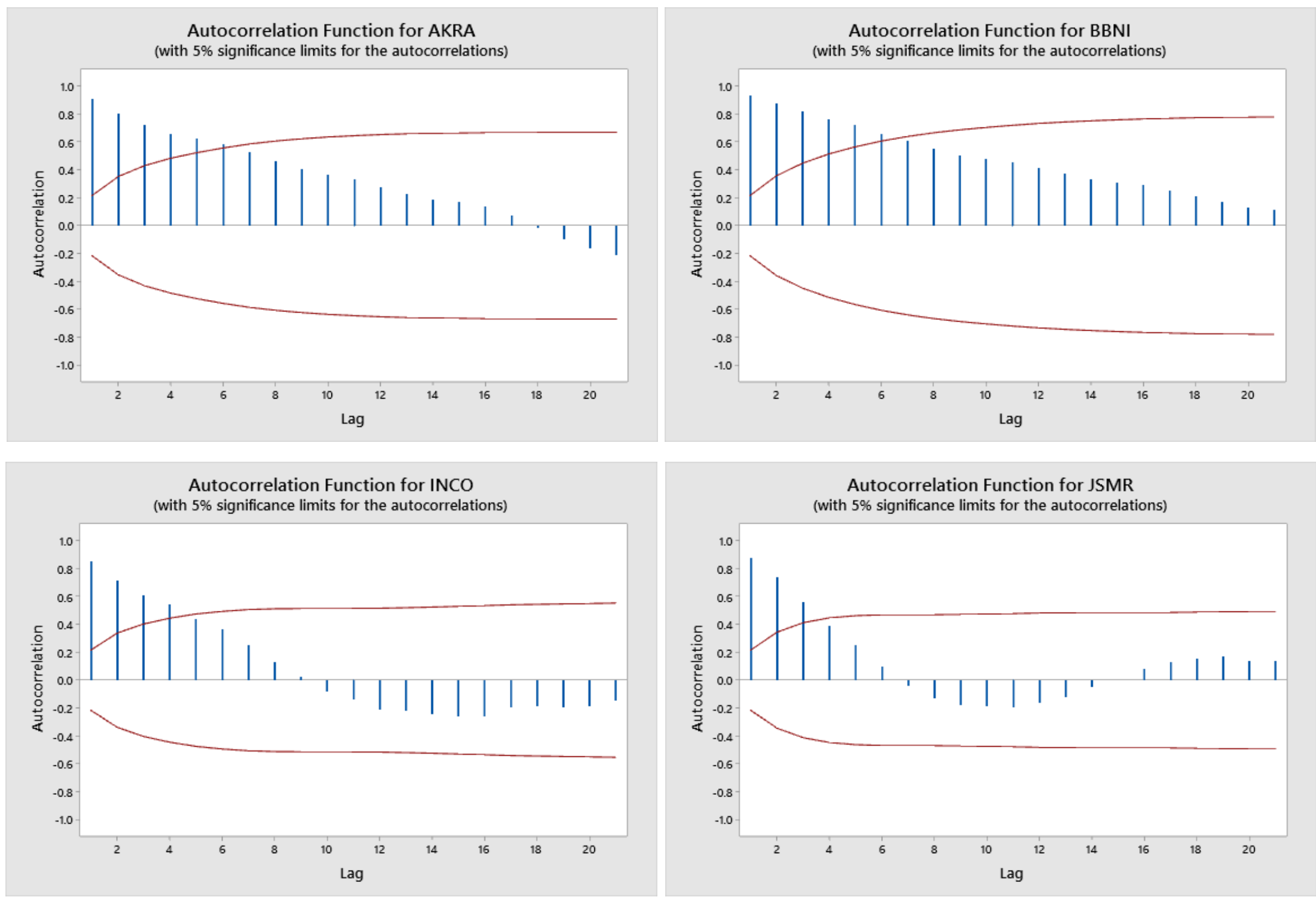

Figure 2. The ACF plots of AKRA, BBNI, INCO, and JSMR stocks 
Figure 2 shows that the autocorrelation coefficients of AKRA and BBNI stocks at lag 1, lag 2, lag 3, lag 4, lag 5, and lag 6 are significantly different from zero, so the ERNN models of both stocks are developed using 6 inputs, namely $y_{t-1}, y_{t-2}, y_{t-3}, y_{t-4}, y_{t-5}$, and $y_{t-6}$. Similarly, the ERNN models of INCO and JSMR are developed using 4 inputs $y_{t-1}, y_{t-2}, y_{t-3}, y_{t-4}$, and 3 inputs $y_{t-1}, y_{t-2}, y_{t-3}$, respectively. The output layer of the ERNN model includes a single neuron $y_{t}$. Backpropagation learning is carried out on normalized stock to obtain weights in each ERNN model.

The data are divided into $75 \%$ for training and $25 \%$ for testing. The monthly stock prices involve 84 periods, since the period of the data is from January 1, 2013, to December 1, 2019. The number of inputs and outputs series is 84 subtracted by the number of variables or lags. For AKRA and BBNI stocks, the training series $y_{t}$ is from period 7 (July 2013) to 65 (Mei 2018) and the testing series is from 66 (June 20018) to 84 (December 2019). While for the INCO and JSMR the training series $y_{t}$ is from period 5 (Mei 2013) to 64 (April 2018) and the testing series is from 65 (Mei 2018) to 84 (December 2019).

The best ERNN model is obtained by finding the optimal number of hidden neurons. It is attempted by trial and error. Here, we try the number of hidden neurons ranging from 1 to 15 . The best ERNN model is established by considering the MAPE training and testing values. The results for all stocks are presented in Table 2 .

Table 2. The MAPE values of ERNN models

\begin{tabular}{|c|c|c|c|}
\hline Stock code & $\begin{array}{c}\text { The number } \\
\text { of hidden neurons }\end{array}$ & Training & Testing \\
\hline AKRA & 11 & 1.5416 & 13.4632 \\
\hline BBNI & 12 & 1.5513 & 12.2596 \\
\hline INCO & 14 & 3.2544 & 21.0572 \\
\hline JSMR & 12 & 2.5934 & 9.0241 \\
\hline
\end{tabular}

Table 2 shows that the ERNN models deliver very high performance in training data, but not the high performance in testing data, especially for INCO stock. The JSMR stock has the highest performance in testing data with the MAPE value below $10 \%$. The best ERNN models for the AKRA, BBNI, INCO, and JSMR stocks have architectures with 6 inputs and 11 hidden neurons, 6 inputs and 12 hidden neurons, 4 inputs and 14 hidden neurons, 3 inputs and 12 hidden neurons, respectively. The results of the ERNN prediction in the testing data are not as satisfied as in training data. The results on the training data are in line with the results of ERNN [14], where the MAPE value is very small. This is not followed by a small MAPE value in testing data. This decreased generalizability is possibly due to the non-stationary conditions of the variables such that the model involves many variables. As stated in Gujarati [26], adding variables will be followed by an increase in accuracy in training data but not necessarily followed by accuracy in testing data.

Although in the testing data the accuracy decreases, the results of the ERNN model have met the white noise error. This test is done by checking the ACF and PACF residuals. The results for the four stocks both in training and testing data are presented in Figure 3, Figure 4, Figure 5, and Figure 6. It can be observed from all figures that each model has met the white noise error because there are no autocorrelation and partial autocorrelation lines that cross the line of significance. Thus, the obtained ERNN models for the four stocks are appropriate.

The stock closing price predictions are yielded by the best ERNN model. Figure 7 displays the comparisons of actual values and ERNN predictions of the stock closing price. It is shown in Figure 7 that in March 2020 the prices of all stocks were dropped. This phenome cannot be cached by the ERNN model, and it leads to a huge error prediction. The stock return prediction is calculated from stock closing price predictions. To specify the investor views, we need to predict the return for three months ahead. The stock closing price and stock return prediction in January, February, and March 2020 are given in Table 3 and Table 4. 

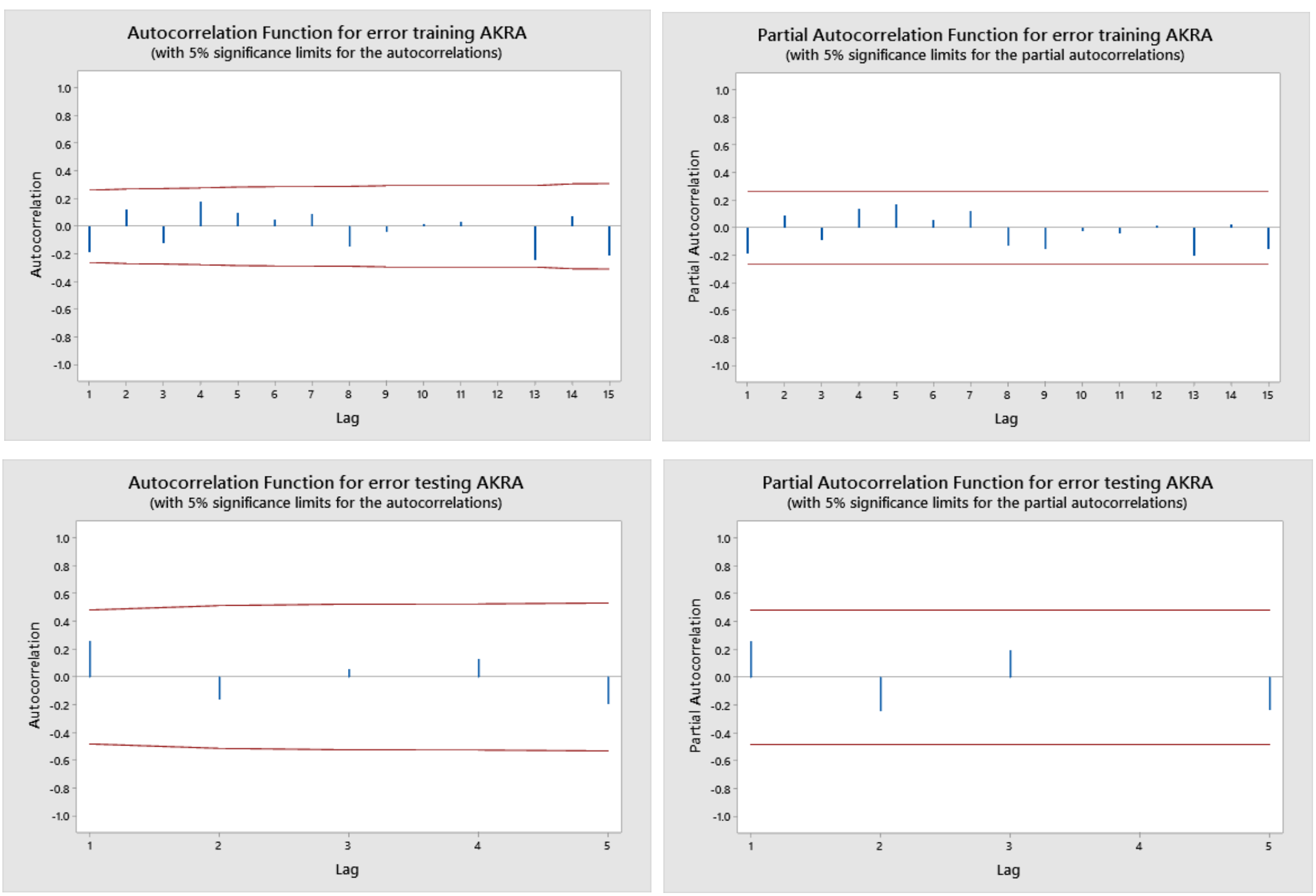

Figure 3. ACF and PACF plots of ERNN model residuals of AKRA stock in training and testing data 

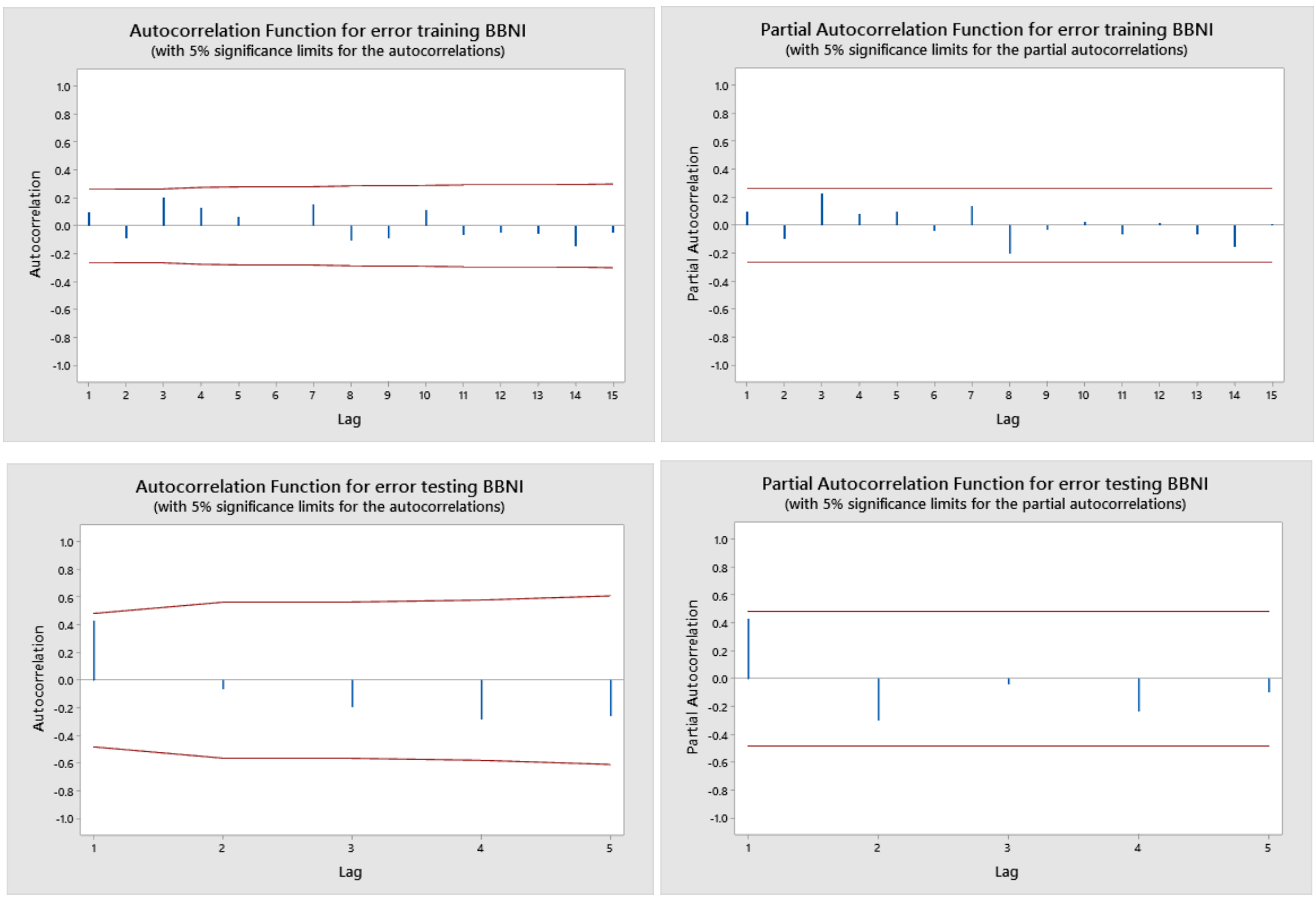

Figure 4. ACF and PACF plots of ERNN model residuals of BBNI stock in training and testing data 

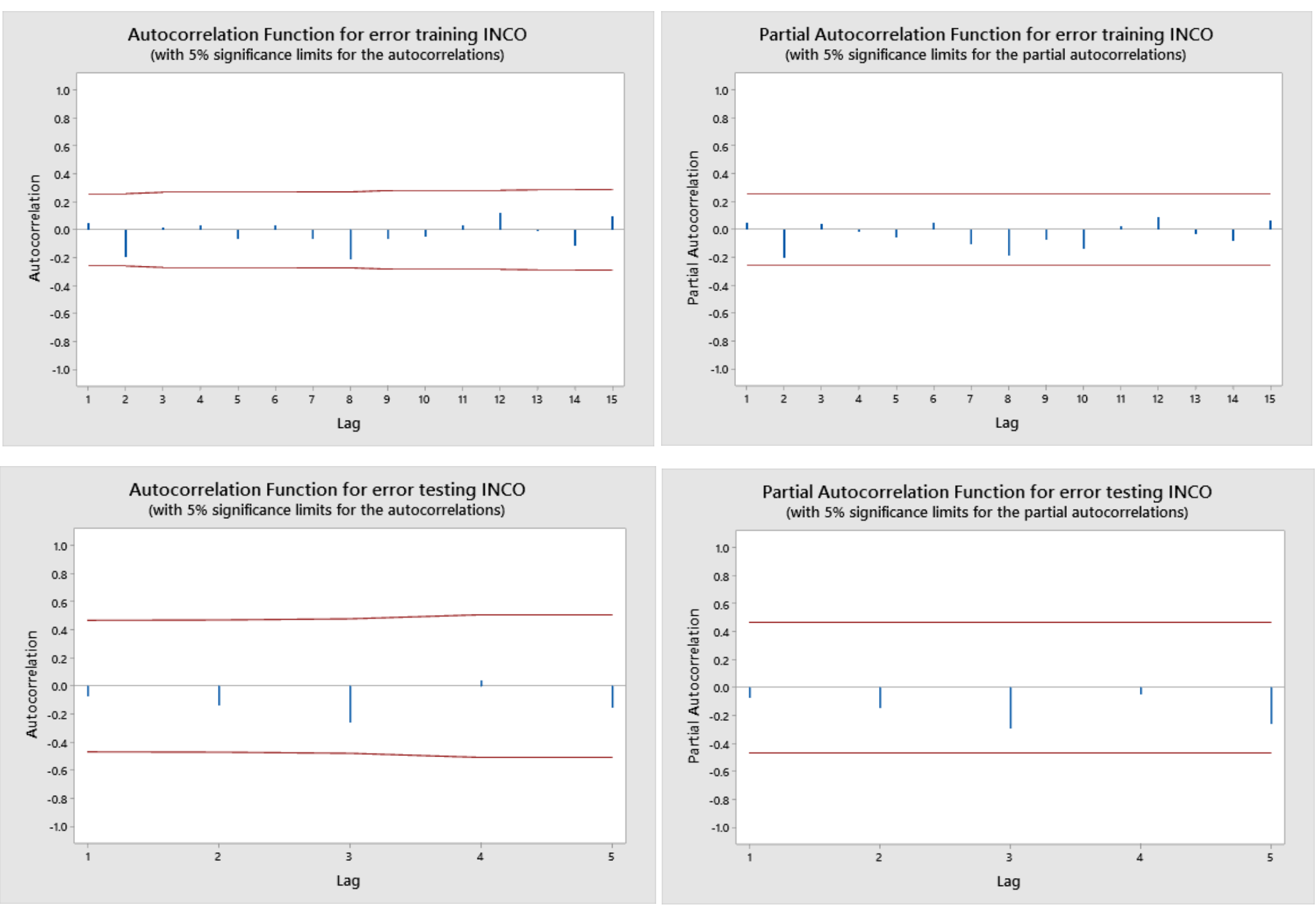

Figure 5. ACF and PACF plots of ERNN model residuals of INCO stock in training and testing data 

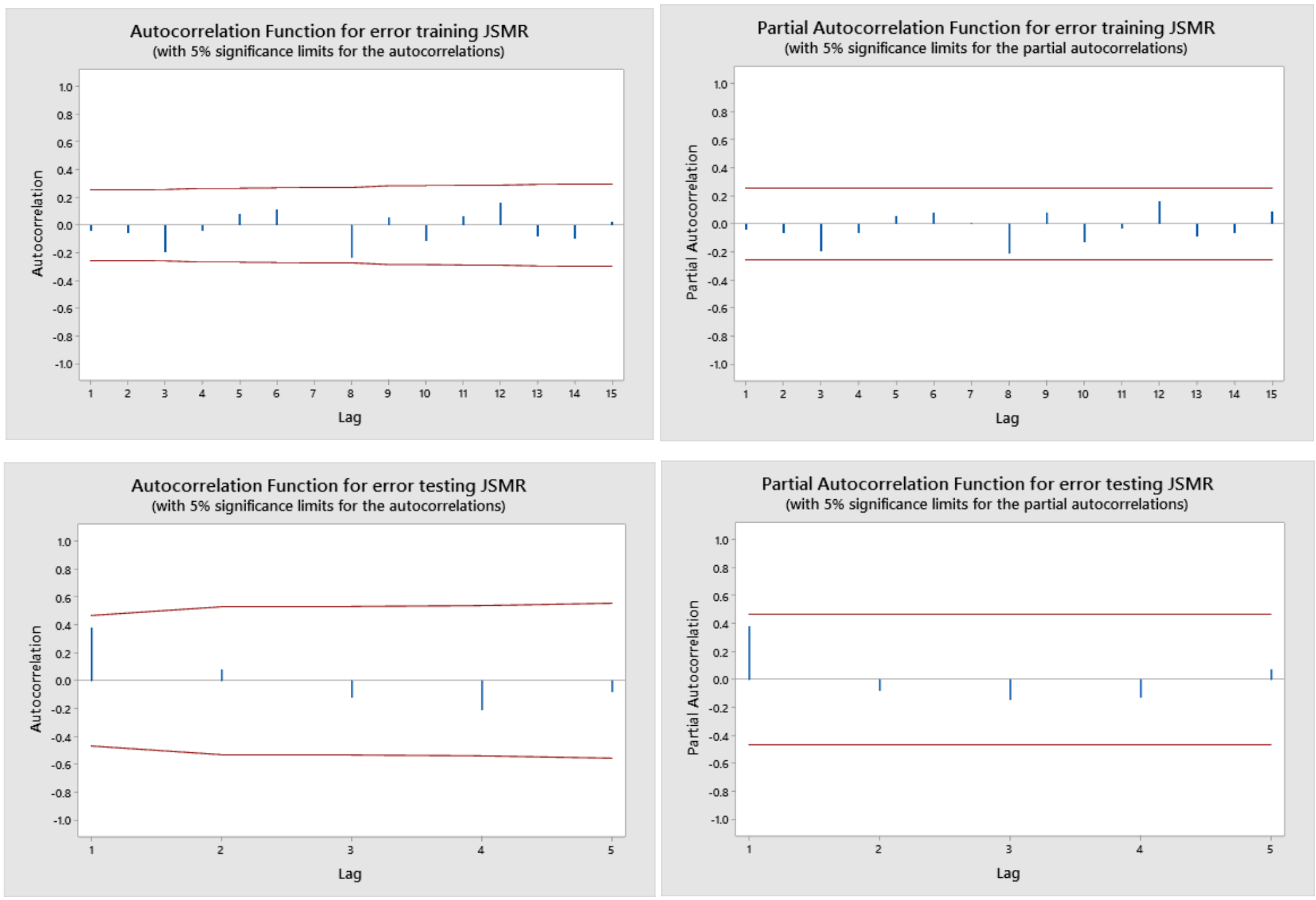

Figure 6. ACF and PACF plots of ERNN model residuals of JSMR stock in training and testing data 

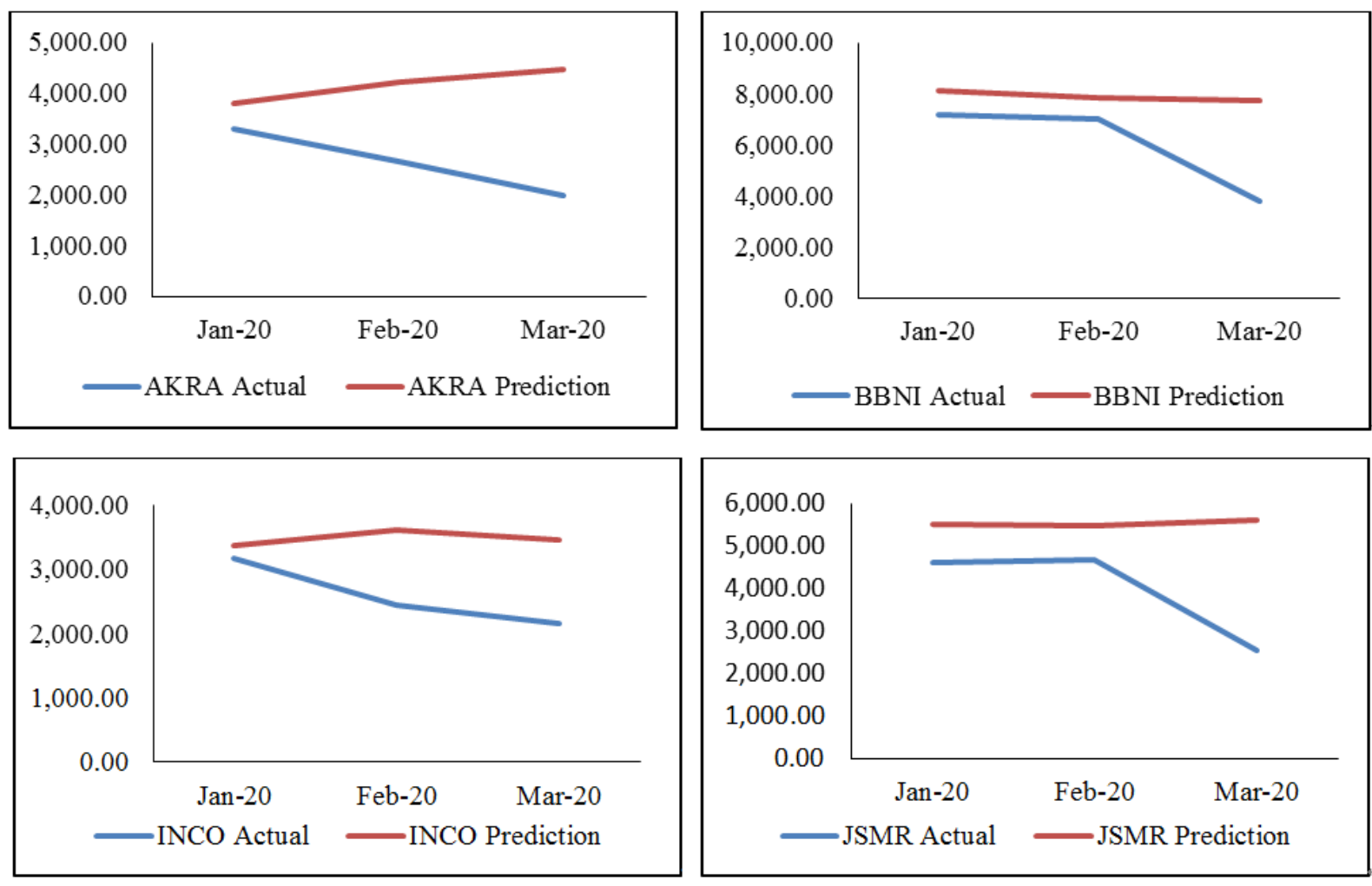

Figure 7. The plots of Actual and ERNN Prediction Stocks

Table 3. Stock closing price prediction

\begin{tabular}{|c|c|c|c|}
\hline \multirow{2}{*}{ Stock code } & \multicolumn{3}{|c|}{ Period } \\
\cline { 2 - 4 } & January 2020 & February 2020 & March 2020 \\
\hline AKRA & 3793.4 & 4209 & 4457.6 \\
\hline BBNI & 8094.1 & 7857.3 & 7755.8 \\
\hline INCO & 3365.9 & 3607.2 & 3458.9 \\
\hline JSMR & 5495.8 & 5474.5 & 5607.5 \\
\hline
\end{tabular}

Table 4. Stock return prediction

\begin{tabular}{|c|c|c|c|}
\hline \multirow{2}{*}{ Stock code } & \multicolumn{3}{|c|}{ Period } \\
\cline { 2 - 4 } & January 2020 & February 2020 & March 2020 \\
\hline AKRA & -0.2434 & 0.1096 & 0.0591 \\
\hline BBNI & 0.1211 & -0.0293 & -0.0129 \\
\hline INCO & 0.2621 & 0.0717 & -0.0411 \\
\hline JSMR & 0.0679 & -0.0039 & 0.0243 \\
\hline
\end{tabular}

The stock return predictions are used to develop a portfolio using views. The views can be set as absolute and relative views as in [10]. In this study, we only consider the relative views since there exist stocks with negatives return predictions. We assign the views of that kind of stock as the difference between the negative stock return and other stock return predictions. Three types of portfolios are generated based on the return prediction in January, February, and March 2020. The views for portfolios I, II, and III, are as follows.

\section{Portfolio I}

View 1: INCO gives a return $50.5431 \%$ more than AKRA

View 2: BBNI gives a return $12.1104 \%$

View 3: JSMR gives a return $6.7954 \%$

The correspond matrix $P=\left[\begin{array}{cccc}-1 & 0 & 1 & 0 \\ 0 & 1 & 0 & 0 \\ 0 & 0 & 0 & 1\end{array}\right]$,

\section{Portfolio II}

View 1: AKRA gives a return 10.9559\%

View 2: JSMR gives a return $2.5380 \%$ more than BBNI

View 3: INCO gives a return $7.1689 \%$

The correspond matrix $P=\left[\begin{array}{cccc}1 & 0 & 0 & 0 \\ 0 & -1 & 0 & 1 \\ 0 & 0 & 1 & 0\end{array}\right]$

\section{Portfolio III}

View 1: AKRA gives a return 5.9064\%

View 2: BNNI gives a return $2.8194 \%$ more than INCO

View 3: JSMR gives a return $2.4945 \%$

The correspond matrix $P=\left[\begin{array}{cccc}1 & 0 & 0 & 0 \\ 0 & 1 & -1 & 0 \\ 0 & 0 & 0 & 1\end{array}\right]$

The elements of the matrix of views coefficient $\mathbf{P}$ in each portfolio are specified relied on views 1 , views 2 , and views 3 . Since there are 4 stocks and 3 views, the 
matrix $\mathrm{P}$ has 4 columns representing the four stocks AKRA, BBNI, INCO, and JSMR, and 3 rows representing 3 views, sequentially. For example, the elements of matrix $\mathrm{P}$ in the portfolio I for the first row are -1 for AKRA and 1 for INCO, and 0 for others, since view 1 states that INCO surpasses the AKRA. The elements of matrix $P$ in the portfolio I for the second row are 1 for BBNI and 0 for others, and elements of matrix $\mathrm{P}$ in the portfolio I for the third row are 1 for JSMR and 0 for others. The next step is to calculate the expected return of Black Litterman using equations (2). In this study, the risk-free return of securities is 0.05 , the tau value is 0.025 , and the risk aversion is 0.025 . The results of portfolio calculations using the BL model are given in Table 5. The weight of each stock obtained is used to calculate the expected portfolio return and portfolio risk. The results are presented in Table 6.

Table 5 shows the negative weights for each portfolio indicating the existence of short sales. It seems that in the portfolio I, the short sale is following the negative BL return prediction for AKRA's stock. When the expectation is negative, the investor can allow the short sale. But it does not occur in portfolios II and III. The short sales do not in line with the negative BL return prediction. These short sales probably are considered from the $\mathrm{P}$ matrix, where the prediction of $\mathrm{BBNI}$ is smaller than JSMR in portfolio II, and the prediction of INCO is smaller than BBNI in portfolio III. Besides, we can observe the results from Table 6 that the highest return as well as the highest risk, are provided by portfolio I.

The portfolio performance is illustrated by simulating an investment. If an investor expends Rp. 100,000,000 in four selected stocks. The actual and predicted profits are provided in Table 7 and Table 8.

Table 7 shows that the actual portfolios I give profits in all months, while actual portfolios II and III only give profits in January. All types of actual portfolios have decreasing performance after January 2020. Based on the actual return, it is recommended for the investor to choose portfolio I. The results in Table 7 and Table 8 demonstrate that the predicted portfolio profits are close to the actual portfolio profits in January 2020 for all types of portfolios. In February and March 2020, the predicted values of portfolios II and III tend to be consistently positive, but the actual profits tend to be negative. The negative trends of the actual portfolio are caused by the downward trend of stock prices due to the spread of coronavirus in February and March 2020. The composite stock price index in January 2020 closed to position 5940.04785, then decreased to position 5452.7011 in February 2020, and 4538.93018 in March 2020. In general, because of the Covid-19 cases at the end of December 2019 in China, the portfolios after January tend to have decrease performances.

Table 5. The BL expected return and portfolio weight

\begin{tabular}{|c|c|c|c|c|c|c|}
\hline \multirow{2}{*}{ Stock code } & \multicolumn{2}{|c|}{ Portfolio I } & \multicolumn{2}{c|}{ Portfolio II } & \multicolumn{2}{c|}{ Portfolio III } \\
\cline { 2 - 7 } & $\boldsymbol{E}\left(\boldsymbol{r}_{\boldsymbol{B} \boldsymbol{L}}\right)$ & $\boldsymbol{w}_{\boldsymbol{B} \boldsymbol{L}}$ & $\boldsymbol{E}\left(\boldsymbol{r}_{\boldsymbol{B} \boldsymbol{L}}\right)$ & $\boldsymbol{w}_{\boldsymbol{B} \boldsymbol{L}}$ & $\boldsymbol{E}\left(\boldsymbol{r}_{\boldsymbol{B} \boldsymbol{L}}\right)$ & $\boldsymbol{w}_{\boldsymbol{B} \boldsymbol{L}}$ \\
\hline AKRA & -0.0291 & -0.764 & 0.0557 & 0.8361 & 0.0312 & 0.6630 \\
\hline BBNI & 0.0599 & 0.6932 & 0.0087 & -0.2275 & 0.0163 & 0.1092 \\
\hline INCO & 0.2189 & 0.768 & 0.0445 & 0.1438 & 0.0012 & -0.0832 \\
\hline JSMR & 0.0478 & 0.3028 & 0.0012 & 0.2476 & 0.0155 & 0.3110 \\
\hline
\end{tabular}

Table 6. The expected return value and portfolio risk

\begin{tabular}{|c|c|c|c|}
\hline & Portfolio I & Portfolio II & Portfolio III \\
\hline Expected return & 0.2464 & 0.059 & 0.0272 \\
\hline Risk & 0.1394 & 0.0818 & 0.0705 \\
\hline
\end{tabular}

Table 7. The actual profit (in Rupiah)

\begin{tabular}{|c|c|c|c|}
\hline Month & Portfolio I & Portfolio II & Portfolio III \\
\hline January 2020 & 11847845 & 14715790 & 9282660 \\
\hline February 2020 & 3349610 & -4197030 & -6819360 \\
\hline March 2020 & 278620 & -22880930 & -17921850 \\
\hline
\end{tabular}

Table 8. The prediction profit (in Rupiah)

\begin{tabular}{|c|c|c|c|}
\hline Month & Portfolio I & Portfolio II & Portfolio III \\
\hline January 2020 & 12441469.4 & 10474999.2 & 9431286.6 \\
\hline February 2020 & 7197260.3 & 22273422.3 & 16215140.3 \\
\hline March 2020 & -2241702.3 & 28520664.5 & 22067088.7 \\
\hline
\end{tabular}




\section{Conclusions}

We have introduced the ERNN to predict views in portfolio construction in the BL model. The performance of the ERNN model is very accurate in training, but less accurate in testing data. In this study, we have not considered performing differencing to get stationary data. This possibly leads to a less accurate prediction in testing data. So, in the next study, we can increase the accuracy of the ERNN model to predict the stock close price by using stationary data.

Three types of portfolios are constructed using different percentages of each return. The performance of the BL portfolio is evaluated by applying the expected return and the weight of the BL model to investment simulation for three months ahead, those are in January, February, and March 2020. Based on the example simulation, the first portfolio delivers the best performance compared to the other two types of portfolios since it gives a positive profit each month while others only give a positive profit in January.

\section{REFERENCES}

[1] E. Tandelilin. Investment Analysis and Portofolio (In Indonesian), Yogyakarta: Kanisius, 2010.

[2] S. Husnan. Fundamentals of Portfolio Theory and Securities (In Indonesian), Fouth Edition, Yogyakarta: UPP AMP YKPN, 2005.

[3] R. Subekti, E. R. Sari, R. Kusumawati. Combining Black-Litterman model with clustering on portfolio construction, Journal of Physics: Conference Series, 2019. DOI:10.1088/1742-6596/1321/2/022051.

[4] K. J. Martin, H. Sankaran, Using the Black-Litterman model: A view on opinions, The Journal of Investing, 28(1):112-122, 2019. https://doi.org/10.3905/joi.2019.1.07 5

[5] B. Q. Ta, T. Vuong. The Black-Litterman model for portfolio optimization on Vietnam stock market, International Journal of Uncertainty, Fuzziness and Knowledge-Based Systems, Vol. 28, No. Supp01, 99-111, 2020. doi:10.1142/S0218488520400097.

[6] F. Yong, B. Lin, Z. Daping, W. Shouyang. Fuzzy views on Black-Litterman portfolio selection model, Journal of Systems Science and Complexity, 31:975-987, 2018. DOI: $10.1007 / \mathrm{s} 11424-017-6330-2$.

[7] S. L. Beach, A. G. Orlov. An application of the Black-Litterman model with EGARCH-M-derived views for international portfolio management, Financial Markets and Portfolio Management, Vol. 21, Issue 2, 147-166, 2007. DOI:10.1007/s11408-007-0046-6.

[8] G. Palomba, Multivariate GARCH models and the Black-Litterman approach for tracking error constrained portfolios: An empirical analysis, Global Business
Economic Review, Vol. 10. Issue 4, 379-413, 2008. DOI:10.1504/GBER.2008.020592.

[9] B. W. Widodo, N. A. Achsani, T. Andati. An application of the Black-Litterman model with ARIMA-ARCH views for Islamic stock portfolio in Indonesian stock exchange, Asian Journal of Bussines \& Management, Vol. 05, Issue 04, 133-140, 2017.

[10] M. Karaa, A. Ulucanb, K. Atici. A hybrid approach for generating investor views in Black-Litterman model, Expert Systems with Applications, 128:256-270, 2019. https://doi.org/10.1016/j.eswa.2019.03.041.

[11] L. S. Maciel, R. Ballini, Neural networks applied to stock market forecasting: an empirical analysis, Journal Brazilian Neural Netwrok Sociaty, Vol. 8, Issue 1, 3-22, 2010. DOI:10.21528/LNLM-vol8-no1-art1.

[12] P. V. Chandrika, K. Sakthi Srinivasan. Predicting Stock Market Movements Using Artificial Neural Networks, Universal Journal of Accounting and Finance, Vol. 9, No. 3, 405 - 410, 2021. DOI: 10.13189/ujaf.2021.090315.

[13] M. Qiu, Y. Song. Predicting the Direction of Stock Market Index Movement Using an Optimized Artificial Neural Network Model, PLoS ONE 11(5): e0155133, 2016. https://doi.org/10.1371/journal.pone.0155133.

[14] D. U. Wutsqa, R. Kusumawati, R. Subekti. The application of Elman recurrent neural network model for forecasting consumer price index of education, recreation and sports in Yogyakarta, Proceeding of 10th International Conference on Natural Computation (ICNC), IEEE, Xiamen, China, August, 192-196, 2014. DOI: 10.1109/ICNC.2014.697583 3.

[15] W. M. Septiawan, S. N. Endah. Suitable recurrent neural network for air quality prediction with backpropagation through time, Proceeding of 2nd International Conference on Informatics and Computational Sciences (ICICoS), IEEE, Semarang Indonesia, 30-31 October, 1-6, 2018. DOI:10.1109/ICICOS.2018.8621720.

[16] X. Liu, J. Deng, J. Yang, Y. Li. Research of a fault prediction method of the electronic equipment based on ARMA - Elman neural network model, Eighth International Conference on Instrumentation \& Measurement, Computer, Communication and Control, 1827-1830, 2018. DOI: 10.1109/IMCCC.2018.00376.

[17] A. K. Palit, D. Popvic. Computational Intelligence in Time Series Forecasting (Theory and Engineering Applications), Springer-Verlag, London, 2005.

[18] G. He, R. Litterman. The intuition behind Black-Litterman model portfolios, Investment Managemen Research, 1999.

[19] F. Black, R. Litterman. Global portfolio optimization, Financial Analysts Journal, Vol. 48(5), 28-43, 1992. https://doi.org/10.2469/faj.v48.n5.28

[20] S. Satchell, A. Scowcroft. A demystification of the Black-Litterman model: Managing quantitative and traditional portfolio construction, Journal of Asset Management, Vol. 1, Issue 2, 138-150, 2000. DOI:10.1057/palgrave.jam.2240011.

[21] D. Ruppert, D. S. Matterson D S. Statistics and Data Analysis for Financial Engineering with R Examples, 
Second Edition, LLC New York, New York, 2011.

[22] J. E. Hanke, D. W. Wichern.Business Forecasting, Eighth Edition, Pearson Education, Inc, New Jersey, 2005.

[23] H. Shrivas, Singhai. Artificial neural network, decision tree, and statistical techniques applied for designing and developing E-mail Cassifier, International Journal of Recent Technology and Engineering, Vol. 1, Issue 6, 164-169, 2013.
[24] S. Kusumadewi. Building Artificial Neural Networks using MATLAB \& EXCEL LINK, Graha Ilmu, Yogyakarta, 2014.

[25] W. W. S. Wei. Time Series Analysis: Univariate and Multivariate Methods, Second Edition, Pearson Education, Inc, New York, 2006.

[26] D. N. Gujarati. Basic Econometrics, Fourth Edition, The McGraw-Hill Companies, New York, 2004. 